\title{
Qualidade de grãos de aveia sob secagem intermitente em altas temperaturas
}

\author{
Quality of oat grains under intermittent drying at high temperatures
}

\author{
Leonor João Marini ${ }^{I}$ Luiz Carlos Gutkoski ${ }^{\mathrm{I} *}$ \\ Moacir Cardoso Elias ${ }^{\mathrm{III}}$ João Anaracy Santin ${ }^{\mathrm{IV}}$
}

\section{RESUMO}

O objetivo deste trabalho foi avaliar o efeito da relação de intermitência e da temperatura do ar de secagem na qualidade de grãos de aveia, armazenados em sistema convencional por 12 meses. Aveia, cultivar "UPF 18”, da safra agrícola 2002/2003 foi submetida à secagem em três temperaturas $\left(65^{\circ} \mathrm{C}, 85^{\circ} \mathrm{C}\right.$ e $\left.105^{\circ} \mathrm{C}\right)$ e a três relações de intermitência (1:2,5, 1:3,7 e 1:5), através de um delineamento composto central rotacional, sendo avaliadas a composição química centesimal, a umidade de armazenamento e a contaminação fúngica dos grãos. Os dados foram submetidos à análise de variância e de regressão polinomial. A secagem intermitente, com temperatura do ar até $65^{\circ} \mathrm{C}$, é um método eficiente para a conservação dos parâmetros biológicos de grãos de aveia branca. Embora diminuam a incidência de contaminação fúngica, temperaturas da massa de grãos acima de $45^{\circ} \mathrm{C}$ durante a secagem provocam redução da qualidade dos grãos de aveia.

Palavras-chave: Avena sativa L, secagem, armazenamento, fungos.

\section{ABSTRACT}

This research was aimed at evaluating the effect of the relationship intermittence and the temperature of the drying air on the physiological and technological quality of oat grains stored in a conventional system for 12 months. Oat, UPF 18 cultivar, harvest in 2002/2003 was submitted to drying at three temperatures $\left(65^{\circ} \mathrm{C}, 85^{\circ} \mathrm{C}, 110^{\circ} \mathrm{C}\right)$ and three intermittent relations $(1: 2,5,1: 3,7,1: 5)$, following a central composite design. After the treatments, it was evaluated the centesimal chemical composition, moisture and fungi contamination of oat grains. The results were analysed through analysis of variance and polynomial regression. The intermittent drying with air temperature until $65^{\circ} \mathrm{C}$ is an efficient method in preserving the biological parameters of the white oat grains. Although it reduces the fungi contamination occurrence, the mass grain temperature over $45^{\circ} \mathrm{C}$ during the drying reduces the quality of oat grains.

Key words: Avena sativa L, drying, storage, fungi.

\section{INTRODUÇÃO}

A produção de aveia no Brasil aumentou de 39 mil toneladas em 1976 para 360 mil toneladas em 2002/2003, representando um crescimento de 923\%, sendo Rio Grande do Sul e Paraná os maiores produtores (Comissão Brasileira de Pesquisa de Aveia, 2003). Além do aumento da disponibilidade interna, também houve melhoria na qualidade industrial dos grãos produzidos em termos de aumento do peso do hectolitro, maior tamanho dos grãos e menor porcentagem de casca. A demanda tem crescido no Brasil, tanto para consumo humano quanto para ração animal. O número de indústrias de processamento de aveia para consumo humano também aumentou significativamente no Brasil (GUTKOSKI, 2000).

A colheita da aveia deve ser realizada estando ela o mais próximo possível da maturidade fisiológica. O retardamento da colheita contribui para a

'Programa de Pós-graduação em Ciência e Tecnologia Agroindustrial, Faculdade de Agronomia Eliseu Maciel, Universidade Federal de Pelotas (FAEM-UFPel), Pelotas, RS, Brasil. E-mail: ljmsj@pop.com.br.

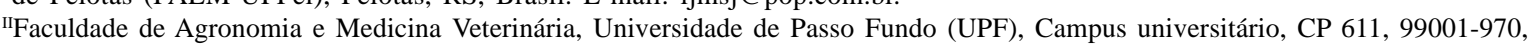
Passo Fundo, RS, Brasil. E-mail: gutkoski@upf.br. *Autor para correspondência.

IIIDepartamento de Ciência e Tecnologia Agroindustrial, FAEM-UFPel, Pelotas, RS, Brasil. E-mail: eliasmc@ufpel.edu.br.

${ }^{\mathrm{IV}}$ Instituto de Ciências Exatas e Geociências, UPF, Campus universitário, Passo Fundo, RS, Brasil. 
deterioração dos grãos, pois equivale a armazená-los a campo, em condições desfavoráveis, expondo-os por um maior período aos agentes patogênicos e estresses ambientais (ELIAS, 2002). A colheita retardada determina ainda a redução do peso do hectolitro e o escurecimento do grão, com a conseqüente depreciação industrial. Se por um lado a colheita antecipada mantém a qualidade do produto, por outro requer secagem para que a qualidade seja mantida durante o armazenamento.

A secagem é o processo de retirada de água dos grãos até um nível que permita o armazenamento por períodos mais longos. Quando o calor necessário para evaporar a água é fornecido ao material, ocorrem transferências simultâneas de calor e massa (CHEN, 2000). A secagem intermitente caracteriza-se pela submissão do grão à ação do ar aquecido na câmara de secagem a intervalos regulares de tempo, intercalados com períodos em que não há circulação de ar, quando o grão passa na câmara de equalização ou repouso. Durante este último período, ocorre homogeneização da umidade, pela migração de água do interior para a superfície do grão (ELIAS, 2002).

Quando a retirada de água é feita de forma muito acelerada, podem ocorrer danos irreversíveis nos grãos. Os danos mais freqüentes, causados quando a secagem por ar aquecido não é convenientemente controlada, são alterações de cor, formação de crosta periférica, perda de matéria seca, redução da integridade física dos grãos, diminuição da digestibilidade das proteínas, desestruturação do amido, suscetibilidade à incidência de defeitos e redução da conservabilidade, além do desperdício de tempo e de energia (ELIAS, 2002).

Os efeitos da secagem em temperaturas elevadas podem não ser imediatos, pois somente após algum tempo de armazenamento tornam-se mensuráveis (AFONSO JUNIOR \& CORRÊA, 2000). A intensidade de danos com efeitos imediatos e latentes, causados em grãos pela secagem, varia de acordo com a espécie e a cultivar, e depende da interação entre a temperatura do ar de secagem e da umidade inicial do produto (FLEURAT-LESSARD, 2002). A COMISSÃO BRASILEIRADE PESQUISADE AVEIA(2003) indica que, durante a secagem de grãos de aveia destinados à industrialização, a temperatura da massa não deve ser superior a $50^{\circ} \mathrm{C}$ e, para o armazenamento, a umidade dos grãos deve ser inferior ou igual a $13 \%$.

Durante o período de armazenamento, fungos xerófilos dos gêneros Aspergillus e Penicillium, chamados fungos de armazenamento, progressivamente substituem os fungos de campo. Entre 0,75 e 0,85 de atividade de água ( $\mathrm{a}_{\mathrm{w}}$ ), espécies de fungos de campo são inibidas ou morrem, enquanto espécies de fungos de armazenamento crescem, embora lentamente. A ação dos fungos é ativada a partir de um limite de atividade de água nos grãos, estando em torno de 0,72 de $\mathrm{a}_{\mathrm{w}}$ na temperatura de $20^{\circ} \mathrm{C}$ (SCUSSEL, 2002).

O objetivo deste trabalho foi avaliar o efeito da relação de intermitência e da temperatura do ar de secagem sobre a qualidade de grãos de aveia.

\section{MATERIAL E MÉTODOS}

Para a realização do trabalho, foram utilizados 1680kg de aveia (Avena sativa L), cultivar “UPF 18”, produzidos no Campo Experimental da Palma, da Universidade Federal de Pelotas - UFPel, no município de Capão do Leão, RS, na safra 2002/2003. As operações de secagem e armazenamento foram realizadas no laboratório de Pós-colheita, Industrialização e Controle de Qualidade de Grãos da Faculdade de Agronomia Eliseu Maciel da UFPel.

A colheita da aveia foi realizada com colhedora automotriz na umidade de $23 \%$ (base úmida) e a pré-limpeza em máquina de ar e peneiras. A secagem intermitente foi realizada em secador piloto modelo Vitória Laboratório, de câmara cilíndrica e fundo cônico centrado com diâmetro de $43 \mathrm{~cm}$, altura da camada de secagem de $32 \mathrm{~cm}$, altura da camada de equalização de $82 \mathrm{~cm}$ e altura do funil de $35 \mathrm{~cm}$. Os parâmetros operacionais do secador foram capacidade estática da câmara de secagem $30 \mathrm{~kg}$, capacidade estática da câmara de equalização $180 \mathrm{~kg}$, capacidade estática total $210 \mathrm{~kg}$, capacidade do elevador $752 \mathrm{~kg} \mathrm{~h}^{-1}$ e velocidade do ar de secagem de $0,72 \mathrm{~m} \mathrm{~s}^{-1}$. Os grãos foram secados até a umidade de $13 \%$ (base úmida), em tempos variando entre 4 horas e 40 minutos e 12 horas, em função das condições experimentais de cada tratamento, e armazenados em sistema convencional pelo uso de sacos de polipropileno de $40 \mathrm{~kg}$ por doze meses. O grau de umidade de colheita dos grãos e de secagem foi determinado por aparelho de condutividade dielétrica.

O delineamento central composto rotacional aplicável à metodologia de superfície de resposta (BOX \& DRAPER, 1987) foi utilizado com a finalidade de estudar o efeito das variáveis temperaturas de secagem $\left(65^{\circ} \mathrm{C}, 85^{\circ} \mathrm{C}\right.$ e $\left.105^{\circ} \mathrm{C}\right)$ e relações de intermitência (1: 2,5 ; $1: 3,7$ e $1: 5,0)$. No experimento, foram empregados sete tratamentos, sendo quatro fatoriais (combinam os níveis-1 e +1) e três no ponto central (as duas variáveis no nível 0 ).

Os grãos foram armazenados no sistema convencional em sacos de polipropileno de $50 \mathrm{~kg}$, pelo período de 12 meses, e realizadas as avaliações de proteínas, lipídios, cinzas, carboidratos, umidade de armazenamento e contaminação fúngica. A temperatura e a umidade relativa média mensal durante os doze meses de armazenamento estão apresentadas na tabela 1 . 
Tabela 1 - Temperatura e umidade relativa média mensal durante os doze meses de armazenamento de aveia cultivar “UPF 18”, em Pelotas, RS.

\begin{tabular}{lcc}
\hline Mês & $\begin{array}{c}\text { Temperatura média } \\
\left({ }^{\circ} \mathrm{C}\right)\end{array}$ & $\begin{array}{c}\text { Umidade relativa } \\
\text { média }(\%)\end{array}$ \\
\hline dezembro de 2002 & 22,3 & 81,4 \\
janeiro de 2003 & 24,1 & 79,8 \\
fevereiro de 2003 & 22,2 & 82,2 \\
março de 2003 & 21,9 & 88,0 \\
abril de 2003 & 19,6 & 85,4 \\
maio de 2003 & 17,1 & 89,9 \\
junho de 2003 & 12,8 & 86,3 \\
julho de 2003 & 12,7 & 86,1 \\
agosto de 2003 & 15,9 & 85,4 \\
setembro de 2003 & 16,1 & 83,7 \\
outubro de 2003 & 18,3 & 83,1 \\
novembro de 2003 & 20,4 & 80,6 \\
dezembro de 2003 & 23,1 & 79,5 \\
\hline
\end{tabular}

Fonte: Estação Agroclimatológica de Pelotas, 2002/2003.

Os teores de proteína bruta, lipídios e cinzas foram determinados de acordo com os métodos preconizados pela AACC (1995), números 46-13, 30-20 e 08-01, respectivamente. Para a determinação de proteína bruta, usou-se o fator 6,25 , e o de carboidratos foi obtido por diferença. Os resultados das análises realizadas com três repetições foram expressos em porcentagem e em base úmida. O grau de umidade dos grãos de aveia foi determinado pelo método da estufa a $105 \pm 3^{\circ} \mathrm{C}$, com circulação natural de ar, por 24 horas, de acordo com a metodologia oficial de análise de sementes preconizada pelas Regras de Análise de Sementes (BRASIL, 1992), sendo os resultados expressos em porcentagem.

A contaminação fúngica foi avaliada pelo teste de papel filtro, de acordo com o método oficial para análise microbiológica de sementes (BRASIL, 1992), e com o emprego de 25 grãos em caixas gerbox. As análises foram realizadas em quadruplicata e os resultados expressos em porcentagem de grãos contaminados. O potencial toxigênico foi obtido pela determinação da porcentagem de grãos contaminados com fungos de pelo menos um dos gêneros Aspergillus, Fusarium e Penicillium.

Os dados obtidos foram avaliados estatisticamente por meio da análise de variância, utilizando-se o teste F, em nível de 5\% de significância, com o emprego do programa estatístico SAS ${ }^{\circledR}$ (SAS INSTITUTE, 1985). Quando alcançada significância estatística, as diferenças entre as médias foram estimadas por meio de análise de regressão polinomial para o fator quantitativo período de armazenamento (meses) e as análises e os gráficos elaborados com o auxílio do programa Microsoft Excel $2000^{\circledR}$, no modo estatístico.

\section{RESULTADOS E DISCUSSÃO}

Na figura 1 estão representados os valores de temperatura máxima e média da massa de grãos durante a secagem intermitente de grãos de aveia branca da cultivar “UPF 18”. Durante a secagem da aveia, as temperaturas médias não ultrapassaram $45^{\circ} \mathrm{C}$, condição essa necessária para que se mantenha a qualidade biológica dos grãos (ELIAS, 2002). Entretanto, nos tratamentos a $105^{\circ} \mathrm{C}$ de temperatura do ar e relação de intermitência de $1: 2,5$ (S2) e de $105^{\circ} \mathrm{C}$ de temperatura do ar e relação de intermitência de 1:5,0 (S4), a temperatura máxima atingida pela massa de grãos foi de $48^{\circ} \mathrm{C}$ e $52^{\circ} \mathrm{C}$, respectivamente, o que pode provocar danos imediatos e latentes que causem perdas na qualidade dos grãos (Figura 1). Os tratamentos realizados a $65^{\circ} \mathrm{C}$ de temperatura do ar e relação de intermitência de 1:2,50 (S1), $65^{\circ} \mathrm{C}$ de temperatura do ar e relação de intermitência de $1: 5,00$ (S3) e $85^{\circ} \mathrm{C}$ de temperatura do ar e relação de intermitência de 1:3,75 (S5) formaram um gradiente similar de secagem, o que demonstra que o sistema intermitente uniformiza a temperatura da massa de grãos quando o ar de secagem não tiver diferenças muito elevadas de temperatura. Da mesma forma, nas secagens S2 e S4, com mesma temperatura $\left(105^{\circ} \mathrm{C}\right)$, porém com diferentes relações de intermitência, os gradientes formados mostraram similaridade.

A composição química, em base úmida, de grãos de aveia com casca da cultivar "UPF 18" foi de 15,1\% de proteínas, 6,9\% de lipídios, 2,1\% de cinzas e $63,2 \%$ de carboidratos (Tabela 2). Esses resultados estão de acordo com os valores obtidos por PEDÓ \& SGARBIERI (1997), que, em estudo de quatro cultivares de aveia, encontraram valores médios de 15,0\% para proteínas, 7,2\% para lipídios e 2,0\% para cinzas. WEBER et al. (2002) e RUPOLLO et al. (2004), estudando a cultivar "UPF 18", encontraram teores de 15,1 e 14,9\%, para proteína bruta e de 7,0 e 6,8\% para lipídios, respectivamente.

O conhecimento das proporções dos constituintes dos grãos é uma informação importante para se prever comportamentos tecnológicos e de conservação dos mesmos. A aveia se caracteriza por apresentar elevados conteúdos de lipídios em comparação com os demais grãos cereais, e isso lhe determina peculiaridades tecnológicas, como, por exemplo, a facilidade de elaboração de flocos. Seu elevado conteúdo lipídico, no entanto, faz com que 


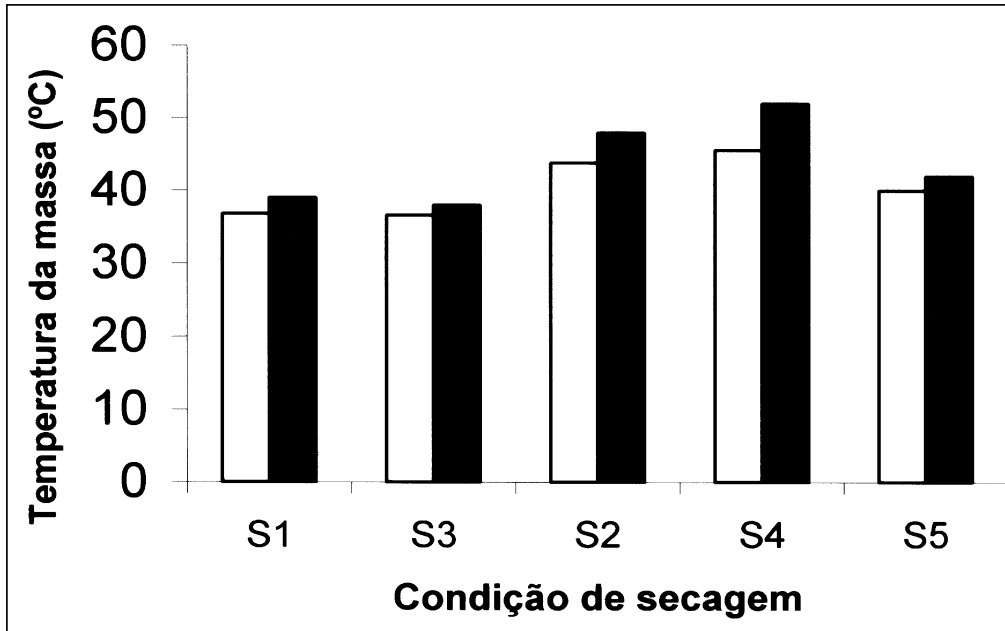

$\square$ Temperatura média

Temperatura máxima

Figura 1- Temperaturas média e máxima da massa de grãos de aveia cultivar "UPF 18”, durante secagem intermitente sob diferentes condições de temperaturas do ar e relação de intermitência (S1: $65^{\circ} \mathrm{C} / 1: 2,5 \mathrm{RI}$; S3: $65^{\circ} \mathrm{C} / 1: 5,0 \mathrm{RI}$; S2: $105^{\circ} \mathrm{C} / 1: 2,5 \mathrm{RI}$; 4 : $105^{\circ} \mathrm{C} / 1: 5,0 \mathrm{RI}$; S5: $\left.85^{\circ} \mathrm{C} / 1: 3,75 \mathrm{RI}\right)$.

sejam necessários cuidados especiais na conservação durante o armazenamento, quando na forma de grãos não processados, pois esses permanecem vivos com metabolismo ativo. A umidade dos grãos analisados, inferior a 13\%, está adequada para o armazenamento (AHRENS et al., 2000).

Em relação à umidade de armazenamento dos grãos, a análise estatística dos dados mostrou que a interação entre condições de secagem e períodos de armazenamento foi significativa (Figura 2). Os resultados mostraram uma variação no grau de umidade dos grãos durante o período de armazenamento, pois esses tendem ao equilíbrio higroscópico, que varia, principalmente, em função da temperatura e da umidade relativa do ar. Os grãos, quando em contato com o ar ambiente, onde a umidade relativa oscila, irão absorver ou ceder água, quando a umidade relativa aumentar ou diminuir. No ponto de equilíbrio higroscópico, a

Tabela 2 - Composição centesimal de grãos de aveia em casca, cultivar "UPF 18".

\begin{tabular}{lcc}
\hline Constituinte & Quantidade (\%) & Desvio padrão \\
\hline Umidade & $12,7^{*}$ & $\pm 0,41$ \\
Proteína bruta (N x 6,25) & 15,1 & $\pm 0,11$ \\
Lipídios & 6,9 & $\pm 0,01$ \\
Cinzas & 2,1 & $\pm 0,06$ \\
Carboidratos $^{1}$ & 63,2 & $\pm 0,09$ \\
\hline
\end{tabular}

*Resultados representam a média de três repetições;

${ }^{1}$ calculado por diferença. pressão de vapor do ar se iguala à pressão de vapor do grão (CHEN, 2000).

Os grãos de aveia apresentaram oscilações no grau de umidade em função das condições de secagem e dos períodos de armazenamento. No tratamento S2, a equação de regressão apresentou comportamento linear reduzindo a umidade com o tempo de armazenamento. Para os tratamentos S3 e S5, as equações de regressão significativas foram de segunda ordem, ocorrendo elevação da umidade até o nono mês de armazenamento e posterior redução. A perda de água para o ambiente foi maior nos primeiros meses de armazenamento, combinando com os meses de temperaturas elevadas e umidades relativas menores (Tabela 1). A partir do terceiro mês, as oscilações de umidade foram menores, porém com tendência de aumento, pois este período coincidiu com os meses de menor temperatura e maior umidade relativa. $\mathrm{Na}$ avaliação final, novamente a umidade diminuiu em conseqüência das alterações nas condições ambientais. De acordo com CHEN (2000), os fatores que mais influenciam no equilíbrio higroscópico de grãos armazenados são composição química, carga genética, ambiente, temperatura de secagem e umidade relativa do ar.

A contaminação fúngica em grãos de aveia foi elevada no início do armazenamento, apresentando diminuição no terceiro mês e um novo aumento no sexto mês (Tabela 3). Esse comportamento acompanhou a variação de umidade dos grãos durante o 


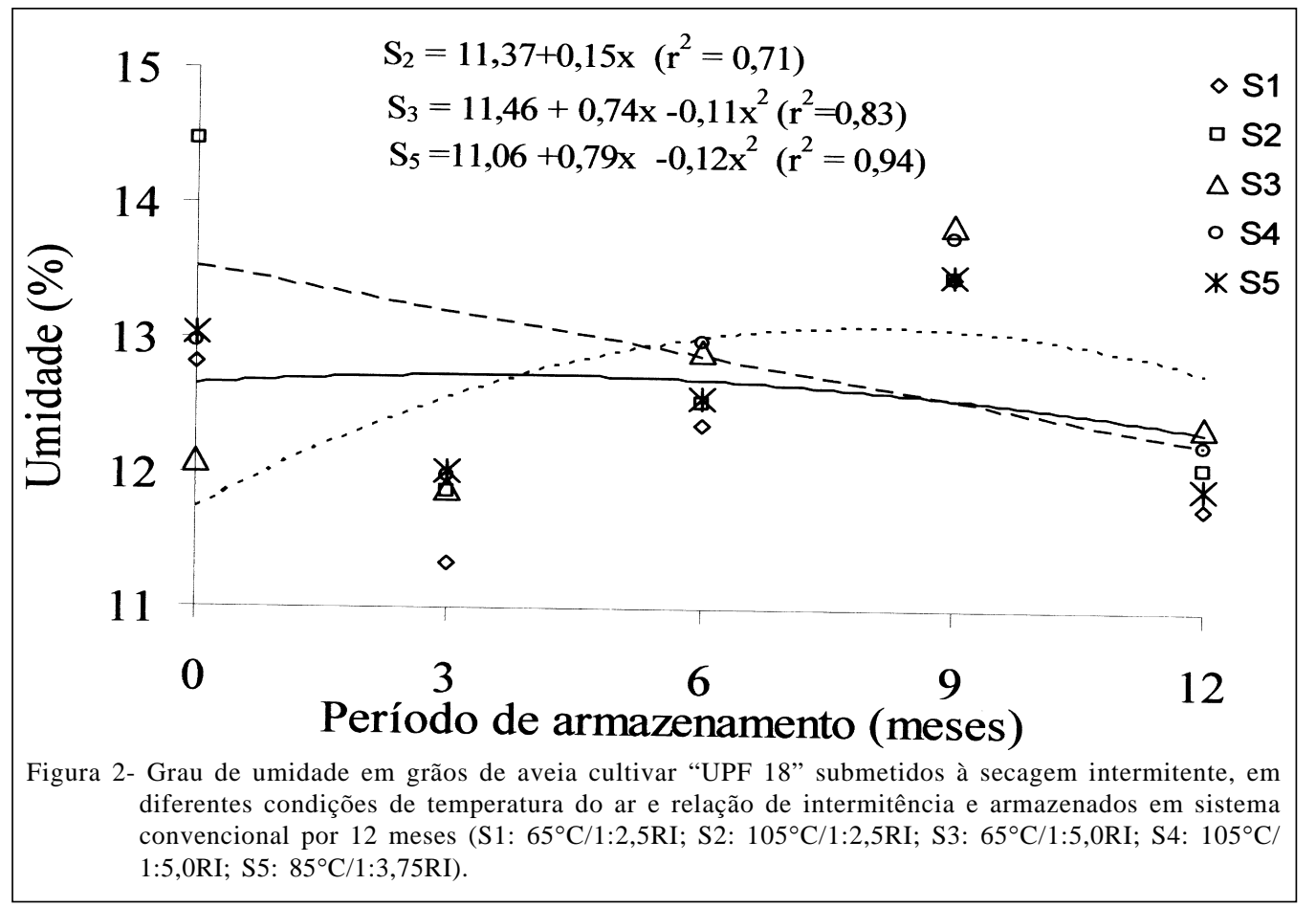

Tabela 3 - Contaminação fúngica em grãos de aveia cultivar "UPF 18” submetidos à secagem intermitente, em diferentes condições de temperatura do ar e relação de intermitência e armazenados em sistema convencional por 12 meses.

\begin{tabular}{|c|c|c|c|}
\hline $\begin{array}{l}\text { Temperatura }\left({ }^{\circ} \mathrm{C}\right) / \text { relação de } \\
\text { intermitência }\end{array}$ & Período armazenamento (meses) & Contaminação fúngica (\%) & Potencial toxigênico (\%) ${ }^{1}$ \\
\hline \multirow{4}{*}{65 / 1:2,50 (S1) } & 0 & 97 & 5 \\
\hline & 3 & 94 & 2 \\
\hline & 6 & 85 & 1 \\
\hline & 12 & 70 & 1 \\
\hline \multirow{4}{*}{105 / 1:2,50 (S2) } & 0 & 96 & 1 \\
\hline & 3 & 49 & 0 \\
\hline & 6 & 74 & 16 \\
\hline & 12 & 56 & 9 \\
\hline \multirow{4}{*}{65 / 1:5,00 (S3) } & 0 & 98 & 2 \\
\hline & 3 & 93 & 1 \\
\hline & 6 & 99 & 20 \\
\hline & 12 & 83 & 4 \\
\hline \multirow{4}{*}{$105 / 1: 5,00$ (S4) } & 0 & 95 & 1 \\
\hline & 3 & 47 & 3 \\
\hline & 6 & 91 & 17 \\
\hline & 12 & 19 & 1 \\
\hline \multirow{4}{*}{85 / 1:3,75 (S5) } & 0 & 99 & 5 \\
\hline & 3 & 84 & 12 \\
\hline & 6 & 96 & 25 \\
\hline & 12 & 55 & 1 \\
\hline
\end{tabular}

${ }^{1}$ Grãos contaminados com fungos de pelo menos um dos três gêneros: Aspergillus, Fusarium e Penicillium. 
armazenamento (Figura 2), pois existe uma influência direta na contaminação por fungos (TANAKA et al., 2001). Nas condições de secagem com temperatura do ar mais elevada (S2 e S4), foi observada menor contaminação fúngica nos grãos em comparação com os tratamentos realizados em menor temperatura.

A maior incidência fúngica no início do armazenamento refere-se, provavelmente, à contaminação vinda da lavoura, ou seja, fungos de campo. Isso também pode ser creditado ao alto grau de umidade, em torno de $23 \%$, em que foi colhida a aveia e ao fato de esses fungos se desenvolverem melhor em umidades relativas do ar mais elevadas, em torno de 90-95\% (TANAKA et al., 2001). Os principais gêneros de fungos de campo patogênicos e saprófitas encontrados foram Bipolaris, Colletotrichum, Alternaria, Fusarium, Rhizopus e Curvularia. Os fungos de campo causam perdas metabólicas nos grãos e, durante o período de armazenamento, são progressivamente substituídos pelos fungos xerófilos, principalmente dos gêneros Aspergillus e Penicillium, chamados fungos de armazenamento.

Apesar de a incidência dos gêneros Aspergillus, Fusarium e Penicillium, denominados de fungos com potencial toxigênico, ter sido baixa, observou-se um aumento aos seis meses de armazenamento, voltando a decrescer de forma geral no final do período (Tabela 3). A baixa incidência de fungos de armazenamento foi devida provavelmente ao grau de umidade dos grãos durante o período de armazenamento estudado, que praticamente não ultrapassou 13\%, exceto no nono mês.

Os fungos de armazenamento apresentam capacidade de sobrevivência em grãos mais secos, porém o desenvolvimento é prejudicado quando a aveia é armazenada em umidades inferiores a 14\% (RUPOLLO et al., 2004). Por outro lado, em condições de elevada umidade e temperatura da massa de grãos, ocorre um maior crescimento de fungos devido ao aumento do metabolismo (FRISVAD, 1995).

\section{CONCLUSÃO}

A secagem intermitente, com temperatura do ar até $65^{\circ} \mathrm{C}$, é um método eficiente para a conservação dos parâmetros biológicos de grãos de aveia branca. Embora reduzam a incidência de contaminação fúngica, temperaturas da massa de grãos acima de $45^{\circ} \mathrm{C}$ durante a secagem provocam redução da qualidade dos grãos de aveia.

\section{REFERÊNCIAS}

AACC - American Association of Cereal Chemists. Approved methods. 9.ed. Saint Paul: AACC, 1995. Paginação irregular.
AFONSO JÚNIOR, P.C.; CORRÊA, P.C. Efeitos imediato e latente da secagem de sementes de feijão colhidas com diferentes níveis de umidade. Ciência e Agrotecnologia, v.24, p.3340, 2000. (Edição especial).

AHRENS, D.C. et al. Secagem intermitente de sementes de aveia branca empregando altas temperaturas iniciais. Revista Brasileira de Sementes, v.22, p.45-52, 2000.

BOX, G.P.; DRAPER, N,R. Empirical model-building and response surfaces. New York: J. Willey \& Sons, 1987. 669p.

BRASIL. Ministério da Agricultura, do Abastecimento e da Reforma Agrária. Secretaria Nacional de Defesa Agropecuária. Regras para análise de sementes. Brasília: MAPA, 1992. 365p.

CBPA- COMISSÃO BRASILEIRA DE PESQUISA DE AVEIA. Indicações técnicas para a cultura da aveia. Passo Fundo: Ediupf, 2003. 87p.

CHEN, C. Factors that effect equilibrium relative humidity of agricultural products. Transactions of the ASAE, v.43, p.673683, 2000 .

ELIAS, M.C. Fatores que influenciam a aeração e o manejo da conservação de grãos. In: LORINI, I. et al. (Ed). Armazenagem de grãos. Campinas: IBG, 2002. p.311-359.

FLEURAT-LESSARD, F. Qualitative reasoning and integrated management of the quality of stored grain: a promising new approach. J ournal of Stored Products Research, v.38, p.191-218, 2002.

FRISVAD, J.C. Mycotoxins and mycotoxigenic fungi in storage. In: JAYAS et al. (Ed.) Stored -grain ecosystems. New York: M. Dekker, 1995. p.251-288.

GUTKOSKI, L.C. Composição química. In: GUTKOSKI, L.C.; PEDO, I. Aveia - composição química, valor nutricional e processamento. São Paulo: Varela, 2000. 191p.

PEDÓ, I.; SGARBIERI, V.C. Caracterização química de cultivares de aveia (Avena sativa L.). Ciência e Tecnologia de Alimentos, v.17, p.78-83, 1997.

RUPOLLO, G. et al. Sistemas de armazenamento hermético e convencional na conservabilidade de grãos de aveia. Ciência Rural, v.34, n.6, p.1715-1722, 2004.

SAS INSTITUTE. User's guide: statistics. 5.ed. Cary, NC, 1985. 956p.

SCUSSEL, V.M. Fungos em grãos armazenados. In: LORINI, I. et al. (Ed.). Armazenagem de grãos. Campinas: IBG, 2002. p.675-804.

TANAKA, M.A.S. et al. Microflora fúngica de sementes de milho em ambientes de armazenamento. Scientia Agrícola, v.58, p.501-508, 2001.

WEBER, F.H. et al. Caracterização química de cariopses de aveia (Avena sativa L.) da cultivar UPF 18. Ciência e Tecnologia de Alimentos, v.22, n.1, p.39-44, 2002. 